\title{
Filtration-histogram based magnetic resonance texture analysis (MRTA) for glioma IDH and 1p19q genotyping
}

Running Title: MRTA for glioma IDH/1p19q genotyping

Authors: Martin A Lewis¹, Balaji Ganeshan², Anna Barnes², Sotirios Bisdas ${ }^{3,4}$, Zane

Jaunmuktane ${ }^{5}$, Sebastian Brandner5 ${ }^{5}$ Raymond Endozo², Ashley Groves², Stefanie C Thust ${ }^{3,4}$

${ }^{1}$ Institute of Neurology, University College London, London, UK.

${ }^{2}$ Institute of Nuclear Medicine, University College London, London, UK.

${ }^{3}$ Lysholm Neuroradiology Department, National Hospital for Neurology and Neurosurgery, London, UK.

${ }^{4}$ Department of Brain Rehabilitation and Repair, UCL Institute of Neurology, London, UK.

${ }^{5}$ Division of Neuropathology, National Hospital for Neurology and Neurosurgery, University College London NHS Foundation Trust, London, UK

\section{Work originated:}

Institute of Nuclear Medicine

University College Hospital

$5^{\text {th }}$ Floor Tower

235 Euston Road

London, NW1 2BU 


\section{Corresponding Author:}

Dr. Stefanie Thust MD FRCR

Consultant Neuroradiologist and Honorary Senior Lecturer

Lysholm Department of Neuroradiology, National Hospital for Neurology and Neurosurgery

Neuroradiological Academic Unit, Department of Brain Rehabilitation and Repair,

Queen Square, London WC1N 3BG, United Kingdom

Phone: 02034483446

Fax: 02034483070

Email: s.thust@ucl.ac.uk 
Filtration-histogram based magnetic resonance texture analysis (MRTA) for glioma IDH and

\section{1p19q genotyping}

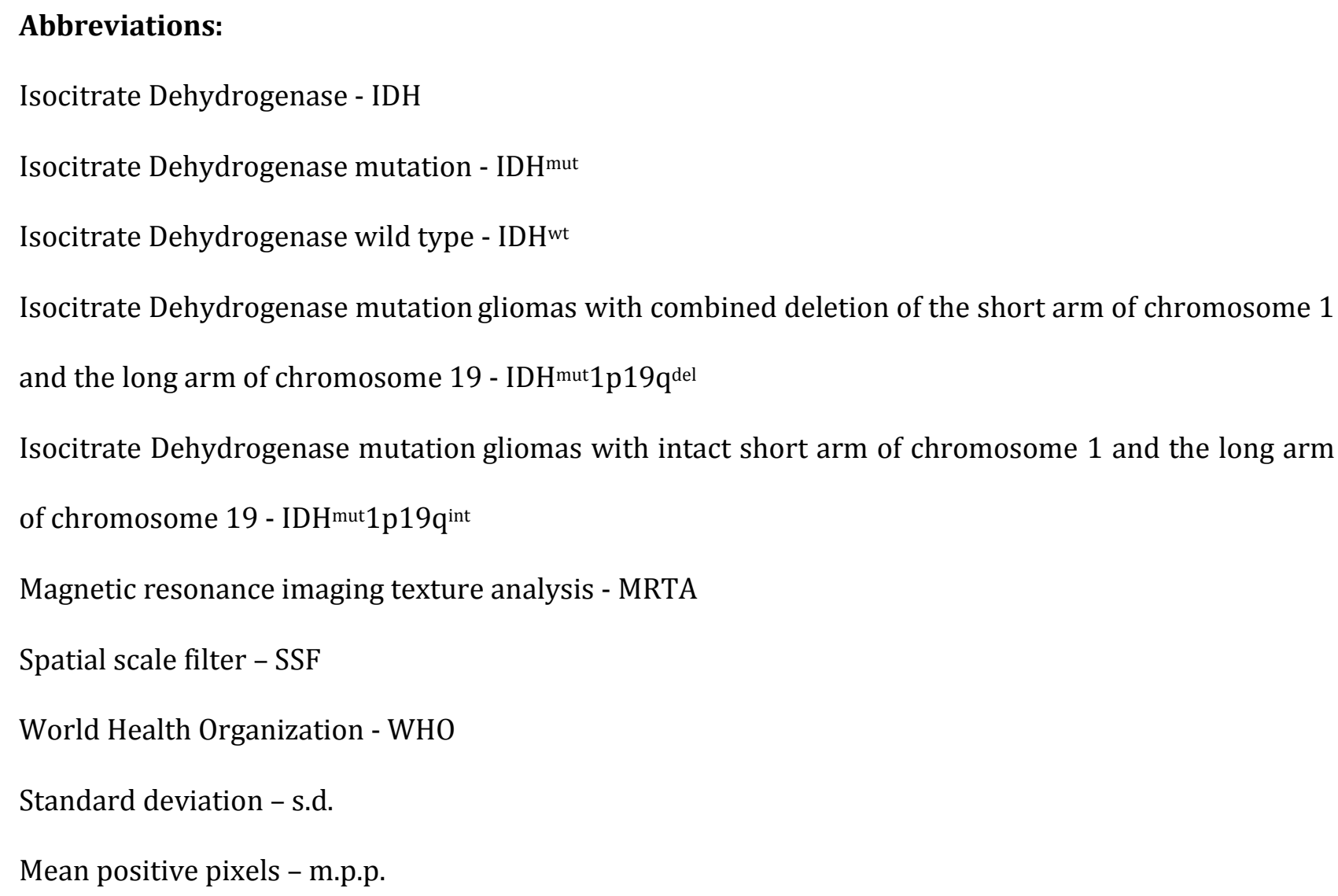




\section{Abstract}

Background To determine if filtration-histogram based texture analysis (MRTA) of clinical MR imaging can non-invasively identify molecular subtypes of untreated gliomas.

Methods Post Gadolinium T1-weighted (T1+Gad) images, T2-weighted (T2) images and apparent diffusion coefficient (ADC) maps of 97 gliomas (54=WHO II, 20=WHO III, 23=WHO IV) between 2010 and 2016 were studied. Whole-tumor segmentations were performed on a proprietary texture analysis research platform (TexRAD, Cambridge, UK) using the software's freehand drawing tool. MRTA commences with a filtration step, followed by quantification of texture using histogram texture parameters. Results were correlated using non-parametric statistics with a logistic regression model generated.

Results T1+Gad performed best for IDH typing of glioblastoma (sensitivity 91.9\%, specificity 100\%, AUC 0.945) and ADC for non-Gadolinium-enhancing gliomas (sensitivity 85.7\%, specificity 78.4\%, AUC 0.877). T2 was moderately precise (sensitivity $83.1 \%$, specificity $78.9 \%$, AUC 0.821 ). Excellent results for IDH typing were achieved from a combination of the three sequences (sensitivity $90.5 \%$, specificity 94.5\%, AUC=0.98). For discriminating 1p19q genotypes, ADC produced the best results using unfiltered textures (sensitivity 80.6\%, specificity 89.3\%, AUC 0.811).

Conclusion Preoperative glioma genotyping with MRTA appears valuable with potential for clinical translation. The optimal choice of texture parameters is influenced by sequence choice, tumour morphology and segmentation method. 


\section{Introduction}

Gliomas exhibit considerable genetic and clinical diversity, even amongst tumors of the same World Health Organization (WHO) histological grade (1). Over 100 DNA mutations have been implicated in glioma genesis (2), from which tumors may be stratified into distinct molecular subgroups of prognostic and predictive value (2-4). As a biomarker, the Isocitrate Dehydrogenase (IDH) gene is pivotal, because a de novo IDH mutation (IDHmut) probably represents the initiating event that distinguishes lower grade (WHO II-III) gliomas from primary glioblastoma (WHO IV) (5). The most common mutation is IDH1R132H, present in $>90 \%$ of lower grade gliomas and in secondary glioblastoma (6). Absence of an IDH mutation (IDH wild-type, IDHwt) is a key feature of primary glioblastoma and defines malignant lower grade gliomas within the same genetic disease spectrum (3). IDHmut gliomas with combined deletion of the short arm of chromosome 1 and the long arm of chromosome 19 (IDHmutp19qdel) are mostly oligodendrogliomas with a better prognosis, which can

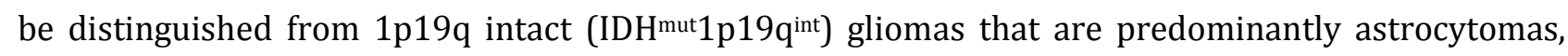
with an intermediate prognosis.

Glioma genotyping by immunohistochemistry depends on tissue sampling and requires facilities for testing, with potential geographical restrictions on turnaround times. Presurgical mutational analysis could influence the timing and extent of tumor resection (7) and predict adjuvant therapy response, for example the sensitivity to temozolomide is greater in IDH'mut gliomas (8).

Morphological assessment can contribute to glioma molecular subtyping $(9,10)$, but limitations include observer dependence and lack of quantitative thresholds. Filtration-histogram based MR imaging texture analysis (MRTA) provides quantitative information about tumor microstructure beyond the limits of visual perception, as reflected by the distribution of pixel values within the lesion (11). MRTA requires no programming skills and is operated by performing a manual tumor segmentation using workstation-integrated software, with calculations initiated via mouse-click. The application commences with a filtration step, which serves to remove image noise, extracts and enhances tissue features of different sizes before measuring signal intensity histogram parameters. The interpretation of results as a reflection of biological processes depends on the tumor type examined, but broadly MRTA provides a measure of tissue heterogeneity. The software has previously 
undergone a qualification process for glioma histological grading and differential diagnosis (12-14). In

1

3

4

5

6

7

8

9

10

11

12

13

14

15

16

17

18

19

20

21

22

23

24

25

26

27

28

29

30

31

32

33

34

35

36

37

38

39

40

41

42

43

44

45

46

47

48

49

50

51

52

53

54

55

56

57

58

59

60

61

62

63

64

65

this study, we investigated whether filtration-histogram based MRTA could predict glioma IDH and 1p19q genotypes using MR images acquired in routine clinical practice. 


\section{Materials and methods}

\section{Patient cohort}

Ethics review board approval was obtained with informed consent waived for this retrospective study of anonymized imaging data. Cases were identified randomly from attendances for operative planning (n=124) between 2010 and 2016. 14 patients were excluded due to a non-glioma histological diagnosis, 11 patients due to prior surgery, and 2 studies had corrupted imaging data. In total, 97 gliomas were eligible for MRTA (Figure 1, SHARDS diagram). The sample size for this analysis was chosen based on previous work with the software algorithm.

\section{MRI Imaging Acquisition}

96 patients had available T2-weighted (T2) sequences, 91 had T1-weighted post Gadolinium (T1+Gad) imaging and 82 had ADC maps (ADC). Our institution is a quaternary neurosurgical centre, therefore the conventional MRI sequences in this study originated from multiple referrers. The imaging was acquired on 44 different machines ( 67 at 1.5 T, 30 at 3T) from all major vendors: 6 GE, 26 Siemens, 11 Phillips and 1 Hitachi scanner. No single MRI machine supplied more than $20 \%$ gliomas of one molecular subtype or WHO grade. The median [min, max] values of the parameters of the T2-weighted images were: TE $=99[17,140] \mathrm{ms} ; \mathrm{TR}=4690[1205,6300] \mathrm{ms}$; in plane resolution $0.65 \times 0.5[0.45 \mathrm{x}$ $0.45,1.13 \times 0.95] \mathrm{mm}^{2}$, slice thickness $=5[4,7] \mathrm{mm}$, interslice gap $=6.5[4,7.15] \mathrm{mm}$. For $\mathrm{T} 1+\mathrm{Gad}$, the median [min, max] values of the parameters were: TE $=10[2.28,26.38] \mathrm{ms}$; $\mathrm{TR}=470[160,740] \mathrm{ms}$; in plane resolution $0.575 \times 0.525[0.45 \times 0.375,1.5 \times 1.9] \mathrm{mm}^{2}$, slice thickness $=5[0.9,7] \mathrm{mm}$, interslice gap $=6.5[0.9,7.15] \mathrm{mm}$. All DWI acquisitions included three diffusion gradients with weighting values $b=0 \mathrm{~s} / \mathrm{mm}^{2}$ and $b=1000 \mathrm{smm}^{2}$; the median [min, max] of the other parameters were: $\mathrm{TE}=95[55,136] \mathrm{ms} ; \mathrm{TR}=3972[2873,8570] \mathrm{ms}$; in plane resolution $1.25 \times 1.2[1.15 \times 1.15,1.8$ $\mathrm{x} 1.8] \mathrm{mm}^{2}$, slice thickness $=5[4,6] \mathrm{mm}$, interslice gap $=6.5[4.5,7] \mathrm{mm}$.

\section{Histopathology}

Following fixation as paraffin blocks, all tissue samples underwent analysis at our institution's neuropathology department according to World Health Organization (WHO) 2016 guidance on 
immunohistochemistry testing and previous published methodology (15). For IDH R132H immune-

negative tumors, multiple gene Sanger sequencing was performed to exclude alternative IDH mutations. A quantitative polymerase chain reaction based copy number assay was used to determine $1 \mathrm{p} / 19 \mathrm{q}$ status.

\section{Image segmentation}

All image interactions were performed blinded to histological and molecular diagnosis, using proprietary texture analysis research software (TexRAD version 3.3, TexRAD Ltd, www.texrad.com, part of Feedback Plc, Cambridge, UK). Segmentations were performed slice by slice with the software's freehand drawing function. For T2, the entire volume of signal abnormality was segmented (Figure 2). For $\mathrm{T} 1+\mathrm{Gad}, 3$ different types of segmentation were completed: the entire region of $\mathrm{T} 1$ signal abnormality (enhancing + non-enhancing tissue, Seg A), the enhancing lesion inclusive of necrosis (enhancing + necrosis, Seg B) and enhancing tissue only (enhancing tissue - necrosis, Seg C) (Figure 3). ADC volumes of interest were defined by manually copying the area of T2 signal abnormality (Figure 2). Segmentations were undertaken by one researcher (M.L.), trained and supervised by a board-certified radiologist specialized in neuro-oncology (S.T., 7 years experience). Slices containing very few $(<250)$ pixels of signal abnormality were excluded to avoid partial volume effects (mean slice size 4803 pixels, range 349 - 15499). In addition, the image with the largest glioma cross-section based on pixel count was subjected to a separate (single slice) evaluation.

\section{MR Texture Analysis (MRTA)}

MRTA in this study follows a previously published method $(13,16)$. The filtration used here corresponds to the spatial scale filter (SSF) values of $0,2 \mathrm{~mm}, 3 \mathrm{~mm}, 4 \mathrm{~mm}, 5 \mathrm{~mm}$ and $6 \mathrm{~mm}$ in width (radius). $\mathrm{SSF}=0$ hereby means no filtration, $\mathrm{SSF}=2 \mathrm{~mm}$ equals a fine texture scale, $\mathrm{SSF}=3-5 \mathrm{~mm}$ a medium texture scale, and SSF $=6 \mathrm{~mm}$ translates to a coarse texture scale (Figure 4). This was followed by quantification of the image texture via measuring histogram and statistical parameters (mean, standard deviation, entropy, mean of positive pixels, skewness, kurtosis) with slice data mathematically interpolated. 


\section{Statistical analysis}

All statistical testing was performed with SPSS 24 (IBM). For each sequence, the ability of the texture features (with and without filtration) to differentiate between the presence and absence of IDH was evaluated using non-parametric Mann Whitney testing. For 1p19q genotyping, Kruskal-Wallis 1 way ANOVA was used. This was repeated over different subgroup analyses e.g. according to WHO grade. For statistically significant results, a receiver operating characteristic (ROC) analysis was undertaken, to determine the area under the curve (AUC), and optimum cut-offs for sensitivity and specificity calculations. A multivariate logistic regression model was generated, to combine the best results from all sequences for IDH genotyping. Pearson coefficient was used to test associations between volumetric and single slice results. Statistics advice was obtained at our institute. 


\section{Results}

\section{Participants}

50 females and 47 males with an average age of 43.3 (27-77) years were included in the study. The histological and molecular characteristics of the patient population are listed in Table 1.

\section{MRTA using T1+Gad}

\section{T1+Gad volumes for IDH typing}

Table 2 summarizes the most significant T1+Gad results for molecular subtyping. For IDH typing, filtered texture parameters produced the best results. When examining all Gadolinium enhancing gliomas (WHO II-IV) together, coarse texture mean derived from Seg A permitted moderately accurate IDH status prediction (sensitivity $72.2 \%$, specificity $74 \%$, AUC $=0.801$ ), with mean signal intensity values being higher in the IDHwt group.

In glioblastoma, using Seg A, mean was the best parameter for IDH genotyping (sensitivity 91.7\%, specificity 88.9\%, AUC = 0.935). Using Seg B, SD represented the most distinctive parameter to predict IDH status (sensitivity 87.5\%, specificity 100\%, AUC $0.906-0.969$ ). With Seg C, kurtosis was the best IDH status predictor across all filters (sensitivity 91.9\%, specificity 100\%, AUC = 0.945) (Figure 5).

\section{T1+ Gad volumes for 1p19 typing}

Combining WHO grades II-III, T1+Gad using Seg A demonstrated moderate results with unfiltered skewness as the best predictor (sensitivity $77.4 \%$, specificity $77.8 \%$, AUC 0.736 ). For WHO III alone, the algorithm performance for mean was better (AUC 0.871).

\section{MRTA using ADC maps}

\section{ADC volumes for IDH typing}

Table 3 summarizes the ROC analysis using ADC volumes for MRTA. Combining WHO II-IV, ADC skewness without filtration performed best for IDH genotyping (sensitivity 77.8\%, specificity 68.7\%, AUC $=0.791)$. 
Including all gliomas with available ADC maps ( $\mathrm{n}=82$ ), unfiltered mean ADC performed moderately for

a threshold of $1135 \mathrm{~mm} / \mathrm{s}^{2}$ (sensitivity 64.1\%, specificity 66.7\%, AUC 0.694). When excluding cases with macroscopic necrosis $(n=11)$ from the analysis, the mean ADC area under the curve improved (sensitivity 68.3\%, specificity 91.9\%, AUC 0.818). By additional exclusion of cases with enhancement lacking necrosis $(n=13)$, the results improved minimally further. For non-enhancing gliomas, the prediction using ADC mean (sensitivity 70.6\%, specificity $100 \%$, AUC 0.840 ) was near that of kurtosis (sensitivity $85.7 \%$, specificity $78.4 \%$, AUC 0.877 ). When removing $1 \mathrm{p} 19 \mathrm{q}$ codeleted gliomas from the analysis, the accuracy of ADC to distinguish IDHwt and IDH ${ }^{\text {mut }} 1 \mathrm{p} 19^{\text {int }}$ was greater across WHO II-IV with further improved results for ADC mean (AUC 0.888), and kurtosis (AUC 0.949).

The algorithm was less able to distinguish IDHwt and IDH ${ }^{\text {mut } 1 p 19 \text { del }}$ ADC features with only one significant result observed for unfiltered skewness (AUC 0.690). But when applied only to nonenhancing gliomas, mean ADC and kurtosis could separate IDHwt and IDH ${ }^{\text {mut }} 1 \mathrm{p} 19 \mathrm{q}^{\text {del }}$ better (AUC 0.79, AUC 0.807 respectively).

\section{ADC volumes for 1p19q typing}

For the detection of the $1 \mathrm{p} 19 \mathrm{q}$ co-deletion in IDHmut, ADC was the most useful sequence. Combining WHO II-III, unfiltered textures predicted 1p19q genotype well (sensitivity 80.6\%, specificity of $89.3 \%$, AUC 0.811). The algorithm performance for ADC mean was marginally greater in WHO II alone (sensitivity 90\%, specificity 85\%, AUC 0.905). In WHO grade III, kurtosis generated the best results (sensitivity $88.9 \%$, specificity $100 \%$, AUC 0.952).

\section{MRTA using T2}

\section{T2 volumes for IDH typing}

Table 4 shows the numerical results for the T2 image segmentation. Overall, T2 texture parameters were less distinctive, but the results reached statistical significance. Combining WHO II-IV, the ability to predict IDH status was highest for unfiltered skewness (sensitivity $83.1 \%$, specificity $78.9 \%$, AUC = 
0.821). There was no improvement in accuracy when excluding necrotic or non-necrotic enhancing gliomas from the T2 analysis.

\section{T2 volumes for 1p19q typing}

T2 appeared more limited for 1p19q typing across WHO grades II-III with medium filtered skewness as the best parameter (sensitivity $75.7 \%$, specificity $62.5 \%$, AUC 0.728). An improved result was observed for WHO III gliomas alone (unfiltered skewness AUC 0.843).

\section{Sequence combination for IDH typing}

A logistic regression model was generated combing the best results from $\mathrm{T} 1+\mathrm{Gad}, \mathrm{T} 2$ and $\mathrm{ADC}$ volumes, merging all WHO grades ( $\left.\mathrm{n}=80,63 \mathrm{IDH}^{\mathrm{mut}} / 17 \mathrm{IDH}{ }^{\mathrm{wt}}\right)$. Since the filtering precedes MRTA, 6 different logistic regressions were undertaken. Each filter was selected in turn and a regression undertaken using the 18 textures derived from the 3 sequences. This was a fast operation, taking less than 30 seconds after tabulating the texture results. Using a ROC analysis of the predicted probabilities $($ AUC $=0.98(\mathrm{CI} 0.955,1))$, the regression model yielded a high sensitivity of $90.5 \%$ and specificity of $94.1 \%$ (SSF 4). The model was statistically significant (Hosmer and Lemeshow test $=0.999$, omnibus $\mathrm{p}$ $<0.001$ ) and demonstrated predictive accuracy (Nagelkerke R Square $=0.826$ ).

\section{Single slice analysis for IDH typing}

For $\mathrm{T} 1+\mathrm{Gad}$, mean remained significant in the single slice analysis, with best results achieved for medium to coarse scale filtration, consistent with volumetric results (sensitivity $72.2 \%$, specificity 69.9\%, AUC 0.786). ADC results showed a profile comparable to volumetric assessment for unfiltered mean (sensitivity 60.9\%, specificity $80.9 \%$, AUC 0.727). The T2 segmentation produced unfiltered skewness as the only significant marker (sensitivity 68.6\%, specificity $79.2 \%$, AUC 0.816 ), also consistent with volumetric analysis. For those textures, which generated significant results in both volumetric and single slice use, the Pearson correlation between the two methods was excellent $(\mathrm{r}=$ 0.956) (Figure 6). 


\section{Discussion}

MRTA has shown ability to identify microstructural disease patterns, including cancer genotypes and chemotherapy response $(17,18)$. We demonstrated its potential value for the non-invasive assessment of glioma IDH and 1p19q status. To our knowledge, this is the first study to present results for low and high grade glioma molecular subtyping using a filtration histogram approach based on conventional MR sequences.

Preoperative genotyping matters for several reasons: in $\mathrm{IDH}^{\text {mut }}$ astrocytoma even small residual volumes of tumour reduce survival (19), however, molecular results are not usually available during surgery. Glioblastoma therapy is considered appropriate for WHO II-III IDHwt gliomas, consisting of maximum safe resection followed by radiotherapy and chemotherapy. But morphologically 'low grade' IDHwt gliomas are at risk of receiving observation only (20).

All three MRI sequences tested in this study could contribute to non-invasive genotyping, whereby $\mathrm{T} 1+$ Gad generated the best results in glioblastoma. Gadolinium enhancement occurs in rapidly proliferating gliomas as a result of pathological neovascularity and blood brain barrier disruption (21). It has been suggested that the extent and morphology of new vessel formation differs by mutational status, with greater vascularity in IDHwt compared to IDHmut (22). These processes are known to develop gradually and could explain why enhancement patterns become more precisely recognized by MRTA towards WHO IV. The comparison of three different T1+Gad segmentation methods highlights that the performance of texture parameters is technique-dependent. Using Seg A, mean values were most diagnostic of IDH status, which may relate to overall tumor contrast uptake intensity. In support of this, a recent study by Yamauchi et al. observed dense contrastenhancement preferentially in IDHwt gliomas (23). With Seg B, SD performed best, probably reflecting greater variability of signal intensity values according to the extent of necrosis. Using the same segmentation technique (Seg B) and parameter (SD), Skogen et al. were able to non-invasively predict glioma WHO grade with MRTA (13). When applying Seg C, kurtosis was most significant suggesting additional differences in microstructural enhancement heterogeneity, which appeared greater for IDHwt gliomas. Our results are consistent with a recent machine learning study, in which T1+Gad supported IDH status prediction especially for WHO IV (24). 
Diffusion-weighted imaging has been widely recognized as a biomarker of cellularity in neoplasia (25).

Reduced ADC values are a feature of malignant gliomas $(26,27)$, however, the occurrence of increased diffusivity in necrosis may confound quantitative assessment. In a previous diffusion tensor study by Tan et al., the accuracy of ADC for IDH typing diminished towards WHO IV (28). Our analysis confirms that macroscopic 'high grade' features impact on diffusion quantification: Mean ADC values showed limited sensitivity and specificity when examining WHO II-IV together, with skewness and kurtosis as markers of heterogeneity (29) achieving better results in this context. On the contrary, kurtosis and mean $\mathrm{ADC}$ were both valuable for IDH typing of gliomas with 'low grade' appearances. This is consistent with recent studies, which highlighted that low mean ADC values are predictive IDHwt status in lower grade gliomas $(10,27,30)$. Amongst IDH mutant gliomas, mean ADC values were best at predicting 1p19q genotype in this study, especially for WHO II. IDHmut1p19del glioma ADC values tend to be intermediate, which may impede its distinction from IDHwt, despite marked differences in survival.

The T2 texture signatures identified as predictive of IDH status were similar to those identified for ADC. This result is in keeping with previous research showing associations between ADC, T2 signal and tissue cellularity in glioma, medulloblastoma and lymphoma (31). However, our T2 derived results are less accurate than reported for WHO II gliomas alone (32).

The single slice analysis showed a strong correlation with the volumetric findings, although it was less distinctive. Using this strategy, MRTA appears sufficiently rapid to be integrated into clinical reporting. Further prospective evaluation is required to determine the respective benefits of whole tumor versus largest cross-section texture analysis in terms of precision versus time expense.

The combination of T1+Gad, ADC and T2 sequences appears excellent in the absence of advanced MRI techniques, which might otherwise be employed to assist presurgical glioma subtyping. The diagnostic results presented here are at least equivalent to the best performing 2HG MR spectroscopy (33), perfusion (22) and artificial intelligence approaches published to date, with potential advantages for clinical translation. In summary, MRTA is an easily applicable image workstation tool with potential to perform IDH and 1p19q genotyping of untreated gliomas based on conventional MRI sequences. 


\section{Limitations}

Our patient cohort included a limited number of IDHwt tumours, particularly in WHO grade II and III. It is unknown whether with a larger sample the MRTA software could achieve IDH genotyping by solely using T1w post Gadolinium sequences as suggested by one previous study (34). Further software development is required to optimize transposing regions of interest from one sequence to another, which would increase time efficiency. The origin of MRI sequences from multiple institutions could have influenced measurements, but as no scanner contributed any particular WHO grade or molecular subtype, a systematic error is unlikely. As discussed in prior research, for ADC mapping the dependence from $T_{1}, T_{2}$ and TR settings is mathematically eliminated (30, 35).

\section{Conclusion}

MRTA is a software platform without machine learning, which can assist the distinction of glioma IDH and $1 \mathrm{p} 19 \mathrm{q}$ molecular subtypes. Results may be optimized through tailoring the choice of MRI sequence(s) to tumor morphology. It also appears possible to predict genetic status using a sequence combination without considering specific lesion features. 


\section{Additional Information}

Ethics approval: Ethics review board approval was obtained with informed consent waived for this retrospective study of anonymized imaging data. The study performed in accordance with the Declaration of Helsinki.

Consent for publication: No personal data presented

Availability of data and materials: The datasets used and/or analyzed during the current study are available from the corresponding author on reasonable request

Conflict of interest: ML, AB, SB, ZJ, SB, RE, AG, SC none relevant. BG is a director, part-time employee of TexRAD Ltd (www.texrad.com part of Feedback Plc, Cambridge, England, UK), and shareholder of Feedback Plc (Cambridge, England, UK), company that develops and markets the TexRAD texture analysis algorithm described in this manuscript.

Funding: No specific funding was obtained for this study

Authorship: ML and ST designed and carried out the study, as well as write the manuscript. The statistical analysis was carried out by ML in liaison with the local (University College London) statistics institute. BG supplied the software access and initial training in the use of segmentation tools for this study. RE assisted with anonymization of the images. AB, SB, ZJ, SB, AG reviewed the final manuscript.

Acknowledgements: None specific 


\section{References}

1. Louis DN, Ohgaki H, Wiestler OD, Cavenee WK, Burger PC, Jouvet A, et al. The 2007 WHO classification of tumours of the central nervous system. Acta neuropathologica. 2007;114(2):97-109.

2. Eckel-Passow JE, Lachance DH, Molinaro AM, Walsh KM, Decker PA, Sicotte H, et al. Glioma Groups Based on 1p/19q, IDH, and TERT Promoter Mutations in Tumors. The New England journal of medicine. 2015;372(26):2499-508.

3. Brat DJ, Verhaak RG, Aldape KD, Yung WK, Salama SR, Cooper LA, et al. Comprehensive, Integrative Genomic Analysis of Diffuse Lower-Grade Gliomas. The New England journal of medicine. 2015;372(26):2481-98.

4. Suzuki H, Aoki K, Chiba K, Sato Y, Shiozawa Y, Shiraishi Y, et al. Mutational landscape and clonal architecture in grade II and III gliomas. Nature genetics. 2015;47(5):458-68.

5. Weller M, Pfister SM, Wick W, Hegi ME, Reifenberger G, Stupp R. Molecular neurooncology in clinical practice: a new horizon. The Lancet Oncology. 2013;14(9):e370-9.

6. Hartmann C, Meyer J, Balss J, Capper D, Mueller W, Christians A, et al. Type and frequency of IDH1 and IDH2 mutations are related to astrocytic and oligodendroglial differentiation and age: a study of 1,010 diffuse gliomas. Acta neuropathologica. 2009;118(4):46974.

7. Beiko J, Suki D, Hess KR, Fox BD, Cheung V, Cabral M, et al. IDH1 mutant malignant astrocytomas are more amenable to surgical resection and have a survival benefit associated with maximal surgical resection. Neuro-oncology. 2014;16(1):81-91.

8. Houillier C, Wang X, Kaloshi G, Mokhtari K, Guillevin R, Laffaire J, et al. IDH1 or IDH2 mutations predict longer survival and response to temozolomide in low-grade gliomas. Neurology. 2010;75(17):1560-6.

9. Villanueva-Meyer JE, Wood MD, Choi BS, Mabray MC, Butowski NA, Tihan T, et al. MRI Features and IDH Mutational Status of Grade II Diffuse Gliomas: Impact on Diagnosis and Prognosis. AJR American journal of roentgenology. 2018;210(3):621-8.

10. Patel SH, Poisson LM, Brat DJ, Zhou Y, Cooper L, Snuderl M, et al. T2-FLAIR Mismatch, an Imaging Biomarker for IDH and $1 \mathrm{p} / 19 \mathrm{q}$ Status in Lower-grade Gliomas: A TCGA/TCIA Project. Clinical cancer research : an official journal of the American Association for Cancer Research. 2017;23(20):6078-85.

11. Kassner A, Thornhill RE. Texture analysis: a review of neurologic MR imaging applications. AJNR American journal of neuroradiology. 2010;31(5):809-16.

12. Skogen K, Ganeshan B, Good C, Critchley G, Miles K. Measurements of heterogeneity in gliomas on computed tomography relationship to tumour grade. Journal of neuro-oncology. 2013;111(2):213-9.

13. Skogen K, Schulz A, Dormagen JB, Ganeshan B, Helseth E, Server A. Diagnostic performance of texture analysis on MRI in grading cerebral gliomas. European journal of radiology. 2016;85(4):824-9.

14. Skogen K, Schulz A, Helseth E, Ganeshan B, Dormagen JB, Server A. Texture analysis on diffusion tensor imaging: discriminating glioblastoma from single brain metastasis. Acta radiologica (Stockholm, Sweden : 1987). 2018:284185118780889.

15. Reuss DE, Sahm F, Schrimpf D, Wiestler B, Capper D, Koelsche C, et al. ATRX and IDH1$\mathrm{R} 132 \mathrm{H}$ immunohistochemistry with subsequent copy number analysis and IDH sequencing as a basis for an "integrated" diagnostic approach for adult astrocytoma, oligodendroglioma and glioblastoma. Acta neuropathologica. 2015;129(1):133-46. 
16. Miles KA, Ganeshan B, Hayball MP. CT texture analysis using the filtration-histogram method: what do the measurements mean? Cancer imaging : the official publication of the International Cancer Imaging Society. 2013;13(3):400-6.

17. Weiss GJ, Ganeshan B, Miles KA, Campbell DH, Cheung PY, Frank S, et al. Noninvasive image texture analysis differentiates K-ras mutation from pan-wildtype NSCLC and is prognostic. PloS one. 2014;9(7):e100244.

18. De Cecco CN, Ganeshan B, Ciolina M, Rengo M, Meinel FG, Musio D, et al. Texture analysis as imaging biomarker of tumoral response to neoadjuvant chemoradiotherapy in rectal cancer patients studied with 3-T magnetic resonance. Investigative radiology. 2015;50(4):239-45.

19. Wijnenga MMJ, French PJ, Dubbink HJ, Dinjens WNM, Atmodimedjo PN, Kros JM, et al. The impact of surgery in molecularly defined low-grade glioma: an integrated clinical, radiological, and molecular analysis. Neuro-oncology. 2018;20(1):103-12.

20. Khan $\mathrm{OH}$, Mason W, Kongkham PN, Bernstein M, Zadeh G. Neurosurgical management of adult diffuse low grade gliomas in Canada: a multi-center survey. Journal of neuro-oncology. 2016;126(1):137-49.

21. Plate KH, Mennel HD. Vascular morphology and angiogenesis in glial tumors. Experimental and toxicologic pathology : official journal of the Gesellschaft fur Toxikologische Pathologie. 1995;47(2-3):89-94.

22. Kickingereder P, Sahm F, Radbruch A, Wick W, Heiland S, Deimling A, et al. IDH mutation status is associated with a distinct hypoxia/angiogenesis transcriptome signature which is non-invasively predictable with rCBV imaging in human glioma. Scientific reports. 2015;5:16238.

23. Yamauchi T, Ohno M, Matsushita Y, Takahashi M, Miyakita Y, Kitagawa Y, et al. Radiological characteristics based on isocitrate dehydrogenase mutations and 1p/19q codeletion in grade II and III gliomas. Brain tumor pathology. 2018.

24. Zhang B, Chang K, Ramkissoon S, Tanguturi S, Bi WL, Reardon DA, et al. Multimodal MRI features predict isocitrate dehydrogenase genotype in high-grade gliomas. Neuro-oncology. 2017;19(1):109-17.

25. Padhani AR, Liu G, Koh DM, Chenevert TL, Thoeny HC, Takahara T, et al. Diffusionweighted magnetic resonance imaging as a cancer biomarker: consensus and recommendations. Neoplasia. 2009;11(2):102-25.

26. Kono K, Inoue $\mathrm{Y}$, Nakayama K, Shakudo M, Morino M, Ohata K, et al. The role of diffusion-weighted imaging in patients with brain tumors. AJNR American journal of neuroradiology. 2001;22(6):1081-8.

27. Leu K, Ott GA, Lai A, Nghiemphu PL, Pope WB, Yong WH, et al. Perfusion and diffusion MRI signatures in histologic and genetic subtypes of WHO grade II-III diffuse gliomas. Journal of neuro-oncology. 2017;134(1):177-88.

28. Tan WL, Huang WY, Yin B, Xiong J, Wu JS, Geng DY. Can diffusion tensor imaging noninvasively detect IDH1 gene mutations in astrogliomas? A retrospective study of 112 cases. AJNR American journal of neuroradiology. 2014;35(5):920-7.

29. Hempel JM, Schittenhelm J, Brendle C, Bender B, Bier G, Skardelly M, et al. Histogram analysis of diffusion kurtosis imaging estimates for in vivo assessment of 2016 WHO glioma grades: A cross-sectional observational study. European journal of radiology. 2017;95:202-11.

30. Thust SC, Hassanein S, Bisdas S, Rees JH, Hyare H, Maynard JA, et al. Apparent diffusion coefficient for molecular subtyping of non-gadolinium-enhancing WHO grade II/III glioma: volumetric segmentation versus two-dimensional region of interest analysis. European radiology. 2018 .

31. Guo AC, Cummings TJ, Dash RC, Provenzale JM. Lymphomas and high-grade astrocytomas: comparison of water diffusibility and histologic characteristics. Radiology. 2002;224(1):177-83. 
32. Zhang X, Tian Q, Wang L, Liu Y, Li B, Liang Z, et al. Radiomics Strategy for Molecular Subtype Stratification of Lower-Grade Glioma: Detecting IDH and TP53 Mutations Based on Multimodal MRI. Journal of magnetic resonance imaging : JMRI. 2018.

33. Choi C, Ganji SK, DeBerardinis RJ, Hatanpaa KJ, Rakheja D, Kovacs Z, et al. 2hydroxyglutarate detection by magnetic resonance spectroscopy in IDH-mutated patients with gliomas. Nature medicine. 2012;18(4):624-9.

34. Yu J, Shi Z, Lian Y, Li Z, Liu T, Gao Y, et al. Noninvasive IDH1 mutation estimation based on a quantitative radiomics approach for grade II glioma. European radiology. 2017;27(8):3509-22. 35. J P. Chapter 2 - pulse sequences for diffusion-weighted MRI. In: Johansen-Berg H BTe, editor. Diffusion MRI Academic Press, San Diego2009 p. pp 11-35. 
1

2

3

4

7

8

10

11

12

13

14

15

16

17

18

19

20

21

22

23

24

25

26

27

28

29

30

31

32

33

34

35

36

37

38

39

40

41

42

43

44

45

46

47

48

49

50

51

52

53

54

55

56

57

58

59

60

61

62

63

64

65 
Table 1. WHO grades, IDH and 1p19 genotypes of glioma population

Table 1. WHO grades, IDH and 1p19 genotypes of glioma population

\begin{tabular}{|c|c|c|c|c|}
\hline WHO grade & Number of gliomas & $\mathrm{IDH}^{w t}(\mathrm{e} / \mathrm{e}+\mathrm{n})^{*}$ & $\begin{array}{c}\text { IDH }^{\text {mut }} 1 p 19 q^{\text {int }} \\
(e / e+n)\end{array}$ & $\begin{array}{c}\mathrm{IDH}^{\mathrm{mut}} 1 \mathrm{p} 19 \mathrm{q}^{\mathrm{del}} \\
(\mathrm{e} / \mathrm{e}+\mathrm{n})\end{array}$ \\
\hline II & 54 & $4(0 / 0)$ & $24(2 / 1)$ & $26(2 / 0)$ \\
\hline III & 20 & $3(1 / 0)$ & $7(1 / 0)$ & $10(4 / 1)$ \\
\hline IV & 23 & $12(11 / 8)$ & $10(5 / 1)$ & 1 \\
\hline Total & 97 & $19(12 / 8)$ & $41(8 / 2)$ & $37(6 / 1)$ \\
\hline
\end{tabular}

* $(\mathrm{e} / \mathrm{e}+\mathrm{n})$ denotes (enhancing/enhancing+necrotic) gliomas within each molecular subgroup. 
Table 2. Volumetric analysis using T1+ Gad

\begin{tabular}{|c|c|c|c|c|c|c|c|c|c|c|c|c|c|}
\hline \multicolumn{14}{|c|}{ T1+Gad for IDH genotyping } \\
\hline \multirow{8}{*}{$\begin{array}{l}\text { WHO } \\
\text { II-IV } \\
\text { Seg A } \\
\text { IDH't= } \\
18 \\
\text { IDH } \\
=73 \\
=\end{array}$} & SSF & Mean & SD & Skewness & Kurtosis & $\begin{array}{c}\text { Sens/Spec } \\
(\%)\end{array}$ & \multirow{8}{*}{$\begin{array}{l}\text { WHO IV } \\
\text { Seg B } \\
\text { IDH Het }=8, \\
\text { IDH Hut }^{\text {mut }} \\
=4\end{array}$} & SSF & Mean & SD & Skewness & Kurtosis & $\begin{array}{c}\text { Sens/Spec } \\
(\%)\end{array}$ \\
\hline & 0 & NS & $0.695^{* *}$ & NS & NS & $66.7 / 61.3$ & & 0 & NS & NS & NS & NS & NS \\
\hline & 2 & $0.752 *$ & $0.743^{*}$ & $0.633^{* *}$ & NS & $72.2 / 71.2$ & & 2 & NS & NS & NS & NS & NS \\
\hline & 3 & $0.764 *$ & $0718 * *$ & $0.737^{*}$ & NS & $83,3 / 685$ & & 3 & NS & 0.938* & NS & NS & $75 / 100$ \\
\hline & & & & & & & & & & & & & \\
\hline & 4 & $0.786^{*}$ & $0.706^{* *}$ & $0.759^{*}$ & NS & $83.3 / 69.9$ & & 4 & NS & $0.969 *$ & NS & NS & $87.5 / 100 \#$ \\
\hline & 5 & $0.800^{*}$ & $0.697^{* *}$ & $0.701^{*}$ & NS & $72.2 / 69.9$ & & 5 & NS & $0.906 *$ & NS & NS & $87.5 / 100$ \\
\hline & 6 & 0.801* & $0.699 * *$ & NS & NS & $72.2 / 74 \#$ & & 6 & NS & NS & NS & NS & NS \\
\hline \multirow{6}{*}{$\begin{array}{l}\text { WHO } \\
\text { IV } \\
\text { Seg A } \\
\text { IDH } \\
12 \\
\text { IDt }= \\
=9\end{array}$} & 0 & NS & $0.769^{*}$ & NS & NS & $66.7 / 100$ & \multirow{6}{*}{$\begin{array}{l}\text { WHO IV } \\
\text { Seg C } \\
\text { IDH }^{\mathrm{wt}}=1 \\
1, \\
\text { IDH }^{\mathrm{mut}}=5\end{array}$} & 0 & NS & NS & NS & $0.836^{*}$ & $91.9 / 100$ \\
\hline & 2 & $0.778^{*}$ & $0.870^{*}$ & $0.880 *$ & NS & $83.3 / 89.9$ & & 2 & NS & NS & NS & $0.927^{*}$ & $91.9 / 100$ \\
\hline & 3 & $0.861^{*}$ & $0.870^{*}$ & $0.917^{*}$ & NS & $83.3 / 100$ & & 3 & NS & $0.855^{*}$ & $0.836^{*}$ & $0.891^{*}$ & $91.9 / 100$ \\
\hline & 4 & $0.935^{*}$ & $0.852^{*}$ & $0.852^{*}$ & NS & 91.7/88.9\# & & 4 & NS & $0.891^{*}$ & $0.782^{*}$ & $0.818^{*}$ & $91.9 / 100$ \\
\hline & 5 & $0.917^{*}$ & $0.824^{* *}$ & $0.769^{* *}$ & NS & $83.3 / 100$ & & 5 & NS & $0.873 *$ & NS & $0.855^{*}$ & $91.9 / 100$ \\
\hline & 6 & $0.907 *$ & $0.815^{* *}$ & NS & NS & $83.3 / 77.8$ & & 6 & NS & NS & NS & $0.945^{*}$ & 91.9/100\# \\
\hline \multicolumn{14}{|c|}{ T1+Gad for 1p19q genotyping of IDH' } \\
\hline & SSF & Mean & SD & Skewness & Kurtosis & $\begin{array}{c}\text { Sens/Spec } \\
(\%)\end{array}$ & \multirow{7}{*}{$\begin{array}{l}\text { WHO III } \\
\text { 1p19q } q^{\text {int }} \\
=7, \\
1 p 19 q^{\text {del }} \\
=10\end{array}$} & SSF & Mean & SD & Skewness & Kurtosis & $\begin{array}{c}\text { Sens/Spec } \\
(\%)\end{array}$ \\
\hline \multirow{6}{*}{$\begin{array}{l}\text { WHO } \\
\text { II-III } \\
1 \mathrm{p} 19 \mathrm{q}^{\mathrm{i}} \\
\mathrm{nt}=31 \\
1 \mathrm{p} 19 \mathrm{q}^{\mathrm{d}} \\
\mathrm{el}=33\end{array}$} & 0 & NS & NS & $0.736^{*}$ & NS & 77.4/77.8\# & & 0 & NS & NS & $0.800^{*}$ & NS & $85.7 / 80$ \\
\hline & 2 & $0.725^{*}$ & NS & NS & NS & $75.8 / 64.5$ & & 2 & $0.871 *$ & NS & NS & NS & $70 / 100 \#$ \\
\hline & 3 & $0.735^{*}$ & NS & NS & NS & $81.8 / 61.3$ & & 3 & $0.886^{*}$ & NS & NS & NS & $70 / 100$ \\
\hline & 4 & $0.735^{*}$ & NS & NS & NS & $78.8 / 61.3$ & & 4 & $0.857^{*}$ & NS & NS & NS & $70 / 100$ \\
\hline & 5 & $0.738^{*}$ & NS & NS & NS & $75.8 / 61.3$ & & 5 & 0.871* & NS & NS & NS & $70 / 100$ \\
\hline & 6 & $0.750 *$ & NS & 0.659 & NS & $75.8 / 61.3$ & & 6 & 0.871* & NS & $0.857^{*}$ & $0.896^{*}$ & $70 / 100$ \\
\hline
\end{tabular}

SSF $=$ spatial scale factor, ${ }^{*}$ p-value $<0.005,{ }^{* *}$ p-value $<0.05$, Bold indicates the texture with the highest AUC for which accuracy is displayed, \# indicates best accuracy, NS indicates not significant 
Table 3. Volumetric analysis using ADC values

\begin{tabular}{|c|c|c|c|c|c|c|c|c|c|c|c|}
\hline \multicolumn{12}{|c|}{ ADC for IDH genotyping } \\
\hline \multirow{7}{*}{$\begin{array}{l}\text { WHO II-IV } \\
\text { IDH }{ }^{w t}=18 \\
I D H^{m u t}=64\end{array}$} & SSF & Mean & Skewness & Kurtosis & Sens/spec (\%) & \multirow{7}{*}{$\begin{array}{l}\text { WHO II-IV } \\
\text { Non- } \\
\text { enhancing } \\
\text { IDH }^{\mathrm{wt}}=7 \\
\mathrm{IDH}^{\mathrm{mut}}=51\end{array}$} & SSF & Mean & Skewness & Kurtosis & Sens/spec (\%) \\
\hline & 0 & $0.694^{* *}$ & $0.791 *$ & $0.734^{* *}$ & 77.8/68.7\# & & 0 & $0.733^{*}$ & $0.843^{*}$ & $0.751^{*}$ & $71.4 / 88.2$ \\
\hline & 2 & NS & NS & NS & NS & & 2 & $0.824 *$ & NS & $0.745^{*}$ & $74.5 / 85.7$ \\
\hline & 3 & NS & NS & $0.694^{* *}$ & $66.7 / 64.9$ & & 3 & $0.832^{*}$ & NS & $0.784^{* *}$ & $70.6 / 85.7$ \\
\hline & 4 & NS & NS & $0.693^{* *}$ & $66.7 / 68.7$ & & 4 & $0.815^{*}$ & NS & $0.787^{* *}$ & $68.6 / 85.7$ \\
\hline & 5 & $0.655^{* *}$ & NS & $0.727^{*}$ & $72.2 / 62.5$ & & 5 & $0.818^{*}$ & NS & $0.849 *$ & $71.4 / 82.4$ \\
\hline & 6 & $0.674^{* *}$ & NS & $0.736^{*}$ & $77.8 / 67.2$ & & 6 & $0.840^{*}$ & NS & $0.877^{*}$ & 85.7/78.4\# \\
\hline \multirow{6}{*}{$\begin{array}{l}\text { WHO II-IV } \\
\text { Excluding } \\
\text { necrotic } \\
\text { gliomas } \\
\text { IDH't }=11 \text {, } \\
\text { IDH }^{\mathrm{mut}}=60\end{array}$} & 0 & $0.753^{* *}$ & 0.811* & $0.755^{* *}$ & 72.7/88.3\# & \multirow{6}{*}{$\begin{array}{l}\text { WHO II-IV } \\
\text { Non- } \\
\text { enhancing } \\
\text { IDH }^{\text {wt }}=7 \\
\text { versus } \\
\text { IDH' } \\
1 \text { p19 q } \\
\text { int }=28\end{array}$} & 0 & $0.847^{*}$ & $0.939 *$ & $0.898^{*}$ & $100 / 85.7$ \\
\hline & 2 & $0.785^{*}$ & NS & $0.736^{* *}$ & $73.3 / 81.8$ & & 2 & $0.872^{*}$ & NS & $0.796^{*}$ & $85.7 / 85.7$ \\
\hline & 3 & $0.809^{*}$ & NS & $0.782 *$ & $71.7 / 81.8$ & & 3 & $0.862^{*}$ & NS & $0.857^{*}$ & $85.7 / 71.4$ \\
\hline & 4 & 0.791* & NS & $0.776^{*}$ & $66.7 / 81.8$ & & 4 & $0.852^{*}$ & NS & $0.847^{*}$ & $78.6 / 71.4$ \\
\hline & 5 & $0.800^{*}$ & NS & $0.800^{*}$ & $66.7 / 81.8$ & & 5 & $0.857^{*}$ & NS & $0.949 *$ & 100/85.7\# \\
\hline & 6 & 0.818* & NS & $0.802^{*}$ & $68.3 / 91.9$ & & 6 & $0.888^{*}$ & NS & $0.934^{*}$ & $100 / 85.7$ \\
\hline \multicolumn{12}{|c|}{ ADC for $1 p 19 q$ genotyping of IDH ${ }^{\text {mut }}$ glioma } \\
\hline \multirow{7}{*}{$\begin{array}{r}\text { WHO II-III } \\
\text { 1p19 } \mathrm{q}^{\text {int }}=31 \\
1 \mathrm{p} 19 \mathrm{q}^{\text {del }}=33\end{array}$} & SSF & Mean $(V$ & HO II only) & Kurtosis & Sens/spec (\%) & \multirow{7}{*}{$\begin{array}{c}\text { WHO III } \\
1 \mathrm{p} 19 \mathrm{q}^{\text {int }}=7 \\
1 \mathrm{p} 19 \mathrm{q}^{\text {del }}=9\end{array}$} & SSF & Mean & Skewness & Kurtosis & Sens/spec (\%) \\
\hline & 0 & 0.811 & $\left(0.905^{*}\right)$ & NS & 95/85\# & & 0 & NS & $0.921^{*}$ & $0.952 *$ & $88.9 / 100 \#$ \\
\hline & 2 & 0.708 & $\left(0.798^{*}\right)$ & NS & $75 / 80$ & & 2 & NS & $0.873^{*}$ & NS & $100 / 71.4$ \\
\hline & 3 & 0.722 & $\left(0.808^{*}\right)$ & NS & $70 / 75$ & & 3 & NS & $0.937^{*}$ & NS & $100 / 71.4$ \\
\hline & 4 & 0.715 & $(0.793 *)$ & NS & $70 / 70$ & & 4 & NS & $0.937^{*}$ & NS & $100 / 71.4$ \\
\hline & 5 & 0.737 & $\left(0.802^{*}\right)$ & NS & $75 / 70$ & & 5 & NS & $0.905^{*}$ & NS & $100 / 71.4$ \\
\hline & 6 & 0.736 & $(0.800 *)$ & NS & $85 / 65$ & & 6 & NS & $0.889 *$ & NS & $100 / 71.4$ \\
\hline
\end{tabular}

SSF $=$ spatial scale factor, ${ }^{*}$ p-value $<0.005,{ }^{* *}$-value $<0.05$, Bold indicates the texture with the highest AUC for which accuracy is displayed, \# indicates best accuracy, NS indicates not significant 
Table 4: Volumetric analysis using T2 values and single slice results for all sequences

\begin{tabular}{|c|c|c|c|c|c|c|c|c|c|c|c|}
\hline \multicolumn{6}{|c|}{ T2 volumes for IDH genotyping } & \multicolumn{6}{|c|}{ T2 volumes for 1p19q genotyping of IDH ${ }^{\text {mut }}$ glioma } \\
\hline \multirow{7}{*}{$\begin{array}{l}\text { WHO II-IV } \\
\text { IDH }^{\mathrm{wt}}=19, \\
\mathrm{IDH}^{\mathrm{mut}}=77\end{array}$} & SSF & Mean & Skew & Kurtosis & Sens/spec (\%) & \multirow{7}{*}{$\begin{array}{c}\text { WHO II-IV } \\
\text { 1p19q } q^{\text {int }}=37 \\
1 \mathrm{p} 19 q^{\text {del }}=40\end{array}$} & SSF & Mean & Skew & Kurtosis & Sens/spec (\%) \\
\hline & 0 & NS & 0.821* & $0.669^{* *}$ & 78.9/83.1\# & & 0 & NS & $0.722 *$ & NS & $73 / 62.5$ \\
\hline & 2 & $0.696^{* *}$ & NS & NS & NS & & 2 & NS & $0.717 *$ & NS & $62.2 / 70$ \\
\hline & 3 & $0.677^{* *}$ & NS & $0.657^{* *}$ & $63.6 / 57.9$ & & 3 & NS & $0.728 *$ & NS & $75.7 / 62.5 \#$ \\
\hline & 4 & $0.668^{* *}$ & NS & $0.717^{*}$ & $61.0 / 73.7$ & & 4 & NS & $0.703^{* *}$ & NS & $73 / 60$ \\
\hline & 5 & $0.658^{* *}$ & NS & $0.706^{*}$ & $63.6 / 73.7$ & & 5 & NS & $0.678 * *$ & NS & $64.9 / 62.5$ \\
\hline & 6 & $0.653^{* *}$ & NS & $0.661^{* *}$ & $57.1 / 68.4$ & & 6 & NS & $0.631^{* *}$ & NS & $59.5 / 55$ \\
\hline \multicolumn{6}{|c|}{ Single slice T1+ Gad for IDH genotyping } & \multicolumn{6}{|c|}{ Single slice ADC for IDH genotyping } \\
\hline \multirow{7}{*}{$\begin{array}{l}\text { WHO II-IV } \\
\mathrm{IDH}^{\mathrm{wt}}=18 \\
\mathrm{IDH}^{\mathrm{mut}}=73\end{array}$} & SSF & Mean & SD & Entropy & Sens/spec (\%) & \multirow{7}{*}{$\begin{array}{l}\text { WHO II-IV } \\
\mathrm{IDH}^{\mathrm{wt}}=18, \\
\mathrm{IDH}^{\mathrm{mut}}=64\end{array}$} & SSF & Mean & Skew & Kurtosis & Sens/spec (\%) \\
\hline & 0 & $0.657^{* *}$ & $0.690^{* *}$ & $0.694^{* *}$ & $77.8 / 61.6$ & & 0 & $0.727^{*}$ & $0.722^{*}$ & $0.724^{*}$ & $67.2 / 66.7$ \\
\hline & 2 & $0.738^{*}$ & $0.711^{*}$ & $0.693^{* *}$ & $66.7 / 76.7$ & & 2 & NS & $0.753^{*}$ & NS & 77.8/64.1\# \\
\hline & 3 & $0.747 *$ & $0.704^{* *}$ & $0.685^{* *}$ & $72.2 / 71.2$ & & 3 & NS & $0.654^{* *}$ & $0.674^{* *}$ & $66.7 / 60.9$ \\
\hline & 4 & $0.778 *$ & $0.695^{* *}$ & $0.670^{* *}$ & $88.9 / 64.4$ & & 4 & NS & NS & $0.681^{* *}$ & $66.7 / 57.8$ \\
\hline & 5 & $0.786^{*}$ & $0.684^{* *}$ & NS & 72.2/69.9\# & & 5 & NS & NS & $0.663^{* *}$ & $66.7 / 64.1$ \\
\hline & 6 & 0.771* & $0.667^{* *}$ & NS & $77.8 / 63$ & & 6 & $0.660^{* *}$ & NS & NS & $61.1 / 56.3$ \\
\hline \multicolumn{6}{|c|}{ Single slice T2 for IDH genotyping } & \multicolumn{6}{|c|}{ Sequence combination for IDH genotyping } \\
\hline \multirow{7}{*}{$\begin{array}{l}\text { WHO II-IV } \\
\mathrm{IDH}^{\mathrm{w}}=19, \\
\mathrm{IDH}^{\mathrm{mut}}=77\end{array}$} & SSF & Mean & SD & skew & Sens/spec (\%) & \multirow{7}{*}{$\begin{array}{l}\text { WHO II-IV } \\
(\mathrm{n}=80)\end{array}$} & SSF & AUC & $\begin{array}{c}\text { Min (95\% } \\
\text { CI) }\end{array}$ & $\begin{array}{c}\text { Max (95\% } \\
\text { CI) }\end{array}$ & Sens/Spec (\%) \\
\hline & 0 & NS & NS & $0.816^{*}$ & $84.2 / 66.2 \#$ & & 0 & $0.937^{*}$ & 0.877 & 0.998 & $88 / 88$ \\
\hline & 2 & NS & NS & NS & NS & & 2 & $0.937^{*}$ & 0.887 & 0.987 & $86 / 94$ \\
\hline & 3 & NS & NS & NS & NS & & 3 & $0.942^{*}$ & 0.894 & 0.990 & $87 / 94$ \\
\hline & 4 & NS & NS & NS & NS & & 4 & $0.980^{*}$ & 0.955 & 1.000 & 90/94\# \\
\hline & 5 & NS & NS & NS & NS & & 5 & $0.895^{*}$ & 0.857 & 1.000 & $90 / 88$ \\
\hline & 6 & NS & NS & NS & NS & & 6 & $0.937^{*}$ & 0.869 & 1.000 & $100 / 83$ \\
\hline
\end{tabular}

SSF $=$ spatial scale factor, ${ }^{*}$ p-value $<0.005,{ }^{* *}$-value $<0.05$, Bold indicates the texture with the highest AUC for which accuracy is displayed, \# indicates best accuracy, NS indicates not significant 
Total sample

$$
\mathrm{N}=124
$$

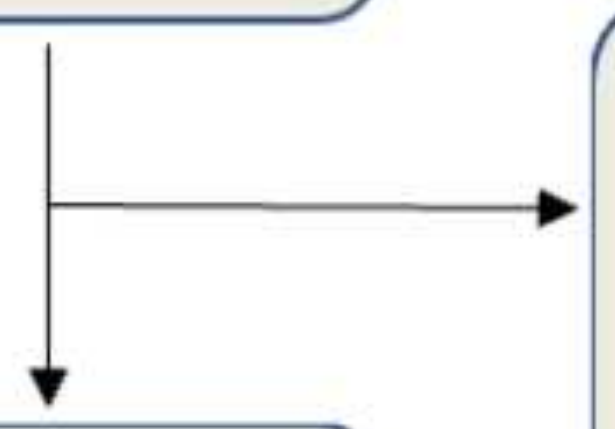

Exclusions $\mathrm{n}=27$

14 non-glioma histology

11 prior surgery

2 corrupted imaging

\section{Eligible patients}

$N=97(50 \mathrm{f} / 47 \mathrm{~m})$

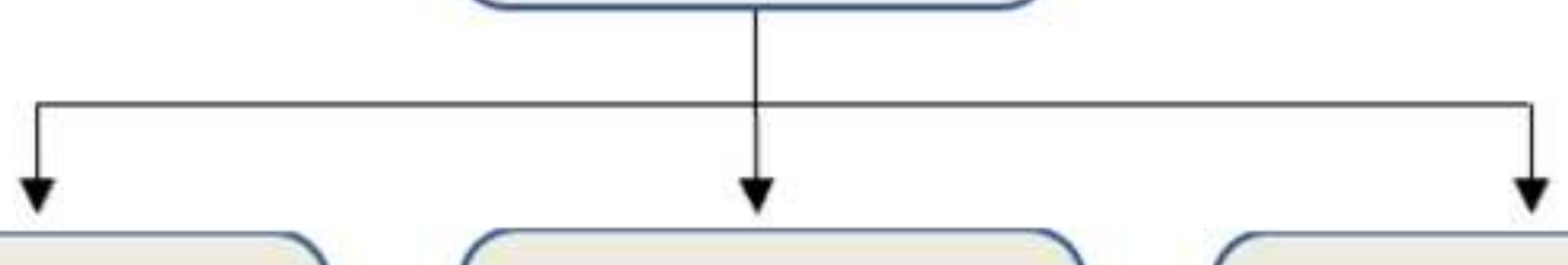

\section{AvailableT2}

Available T1+Gad

$$
\mathrm{N}=96
$$

$$
\mathrm{N}=91
$$

Available ADC

$$
\mathrm{N}=82
$$


Click here to download high resolution image
Cigure 2

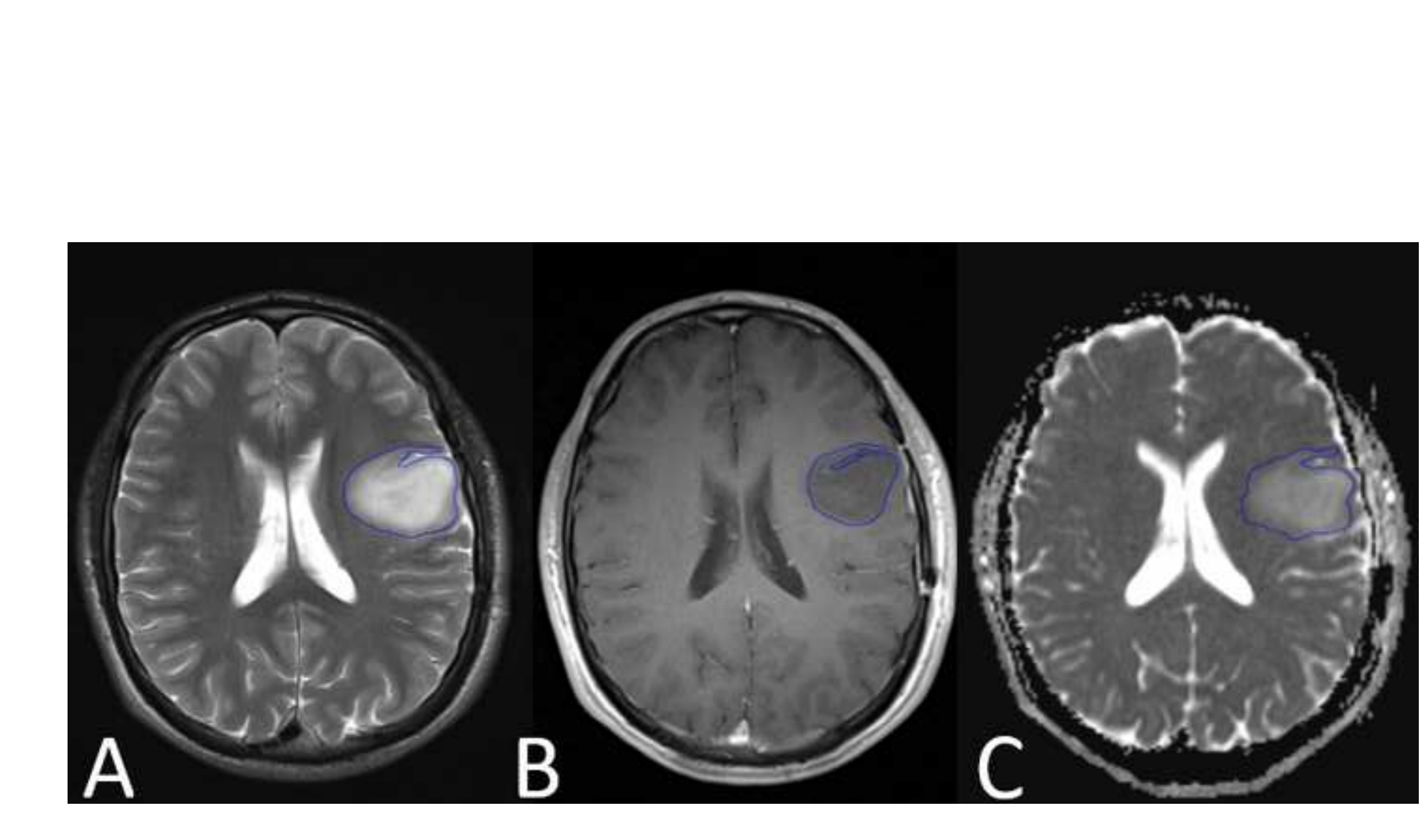

to download high resolution image

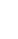

.
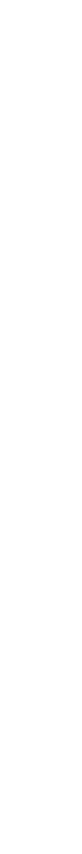
Figure 3
Click here to download high resolution image

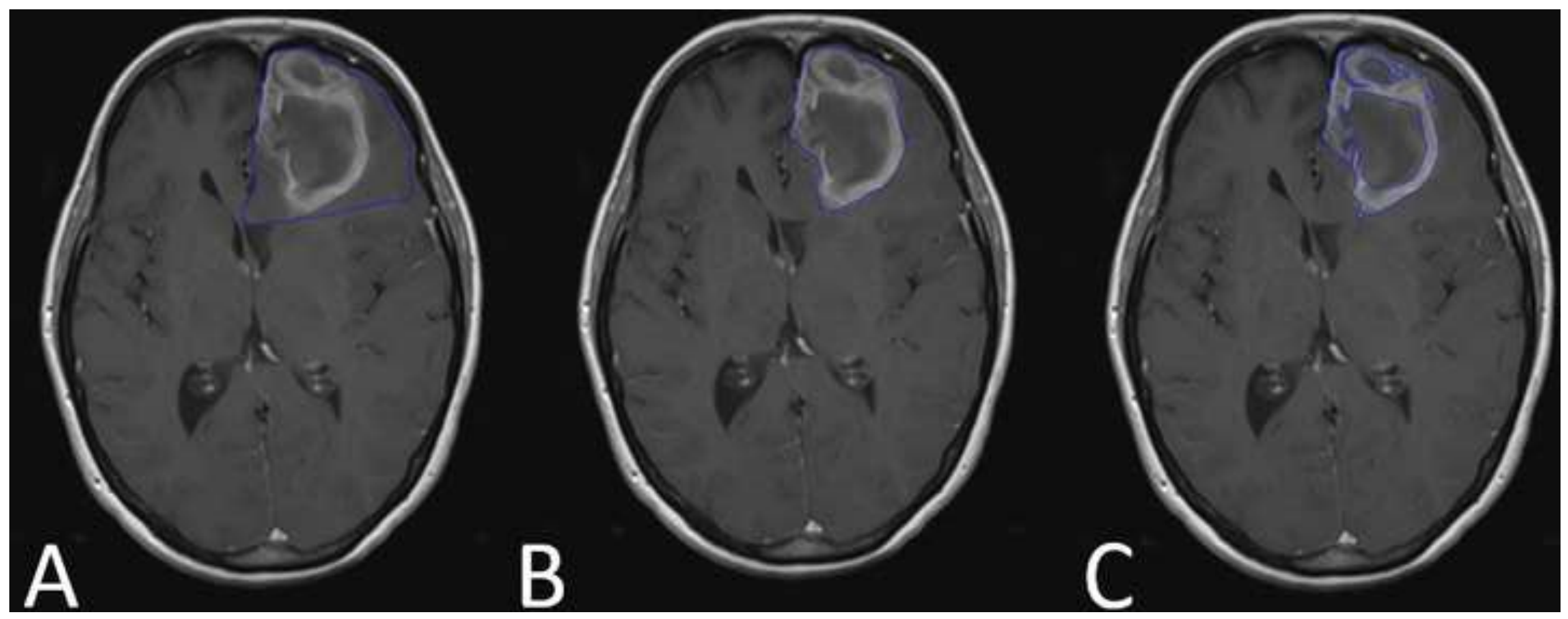


Figure 4
Click here to download high resolution image
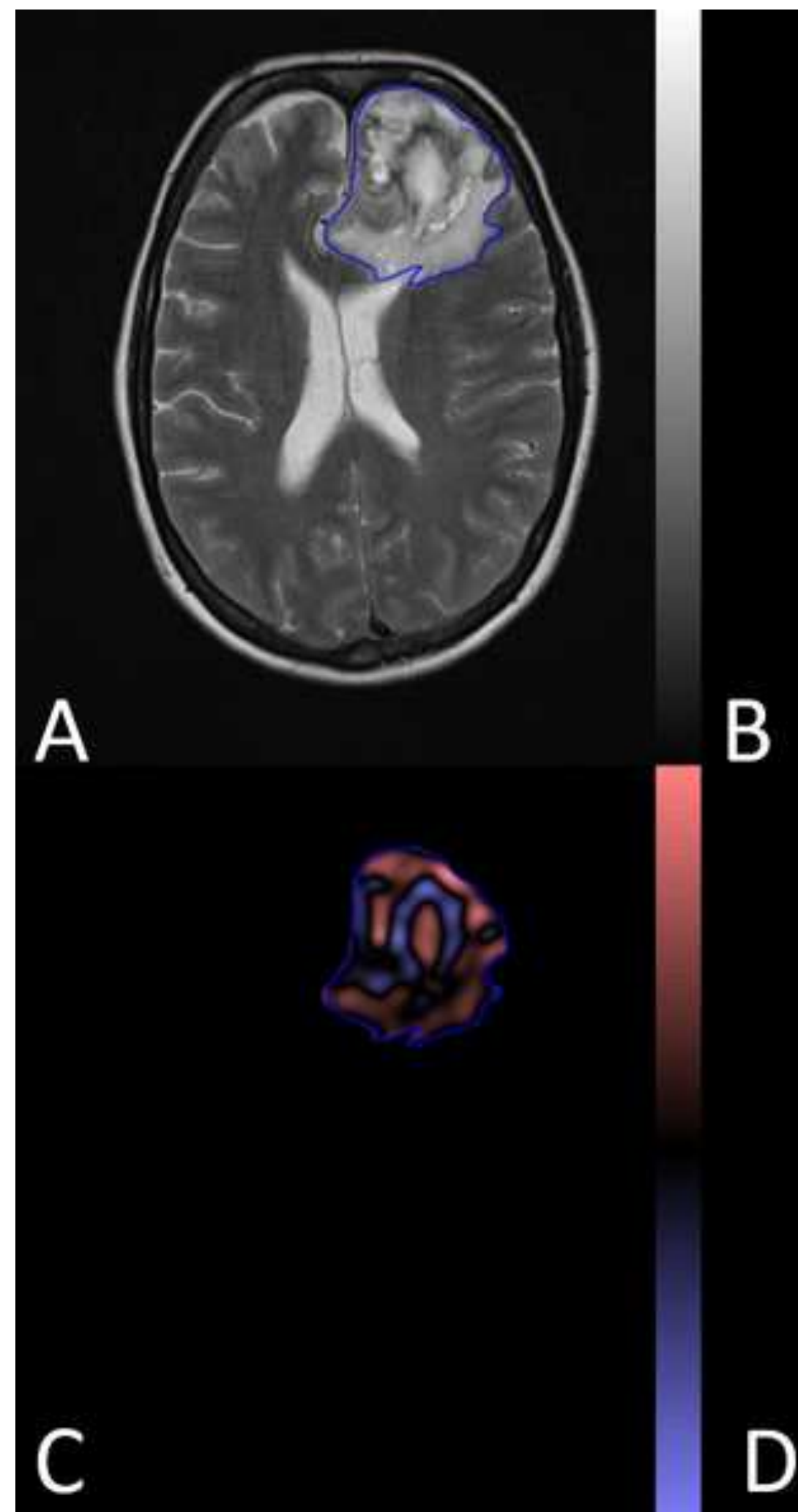
Figure 5
Click here to download high resolution image
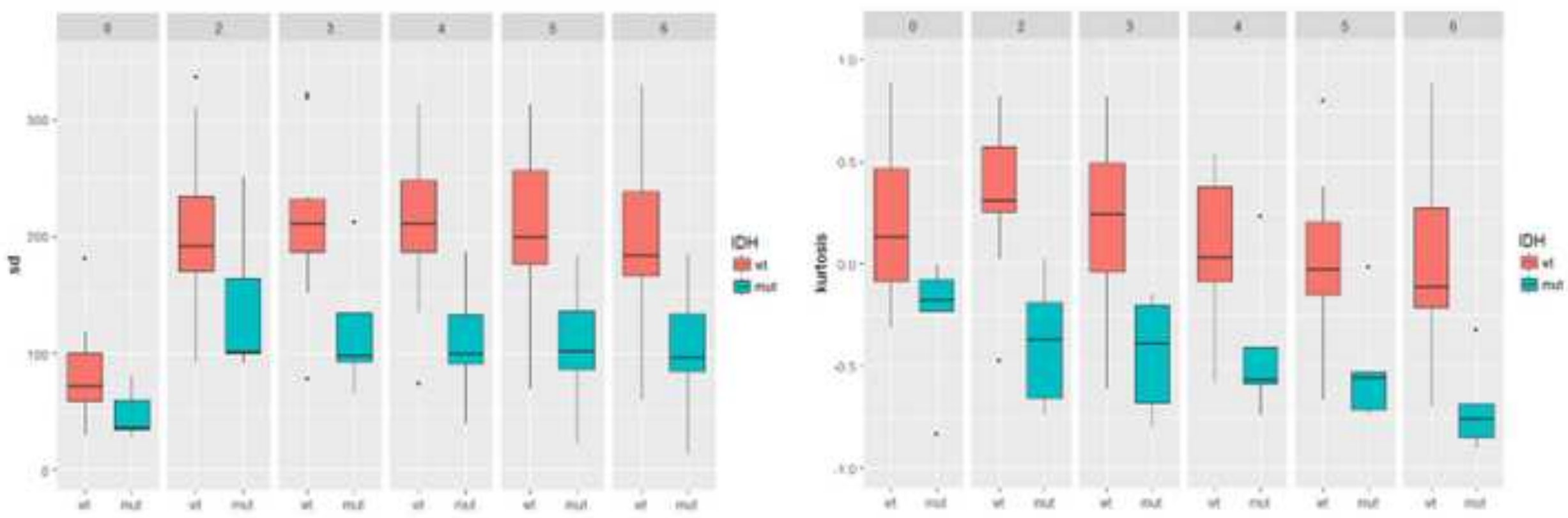

ton

mat 
Click here to download high resolution image

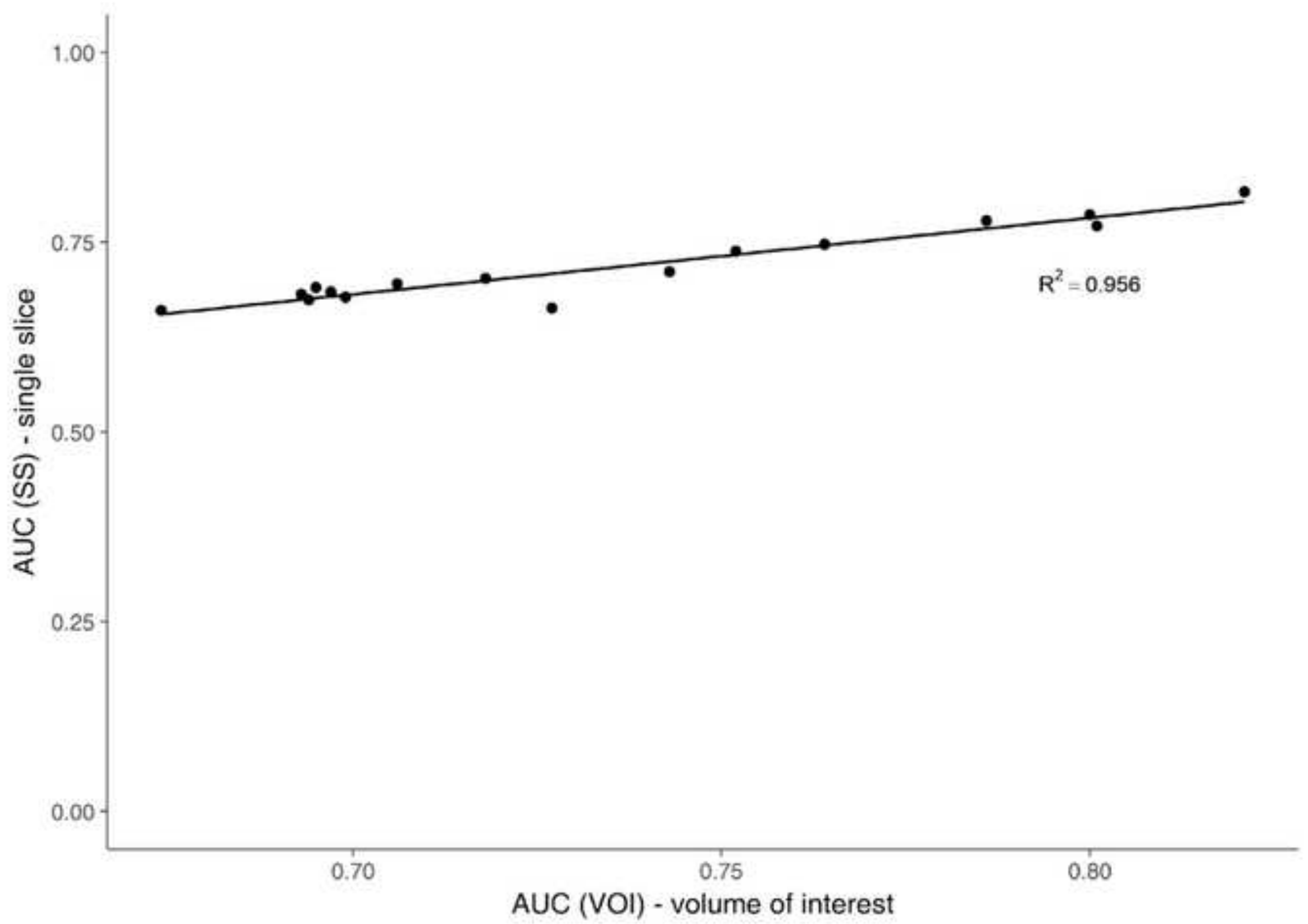


Figure Legends
Click here to download Supplementary File(s): Figure Legends_EJR.docx Click here to download Supplementary File(s): Figure Legends EJR.docx

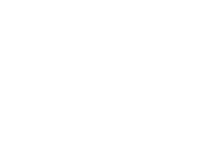

$\sqrt{3}$

$\sqrt{2}$

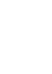

(1)

$\sqrt{3}$

(1)

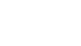
(1) . . . . . . . . . . . . . . . . . . .

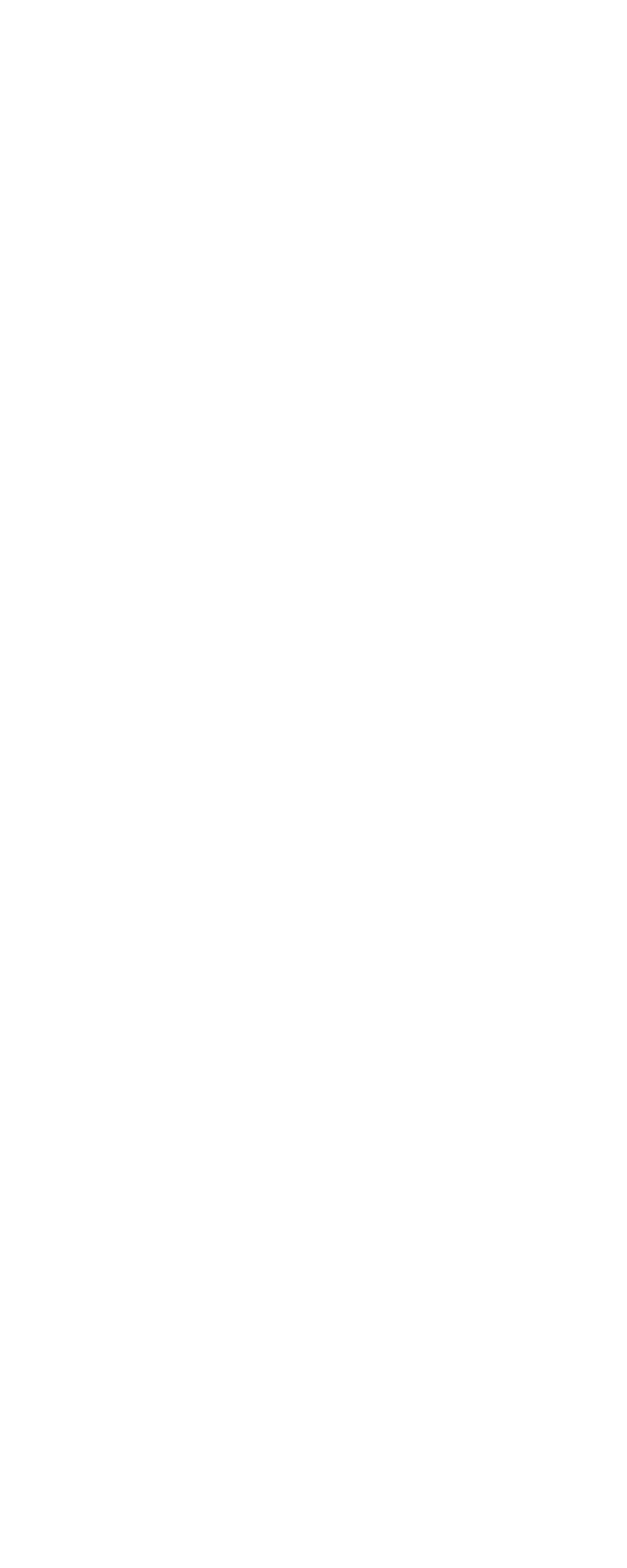
to (1) 